\title{
Sécurité foncière et gestion de la fertilité des sols : études de cas au Ghana et au Bénin
}

\author{
Aliou Saïdou ${ }^{1,4}$ \\ Samuel Adjei-Nsiah² \\ Dansou Kossou ${ }^{1}$ \\ Owuraku Sakyi-Dawson ${ }^{3}$ \\ Thomas W. Kuyper ${ }^{4}$ \\ ${ }^{1}$ Faculté des sciences agronomiques, \\ Université d'Abomey-Calavi, \\ $01 \mathrm{BP} 526 \mathrm{RP}$, \\ Cotonou, \\ Bénin \\ <kossoudansou@yahoo.com> \\ <saidoualiou@gmail.com> \\ ${ }^{2}$ Agricultural Research Centre - Kade, \\ Institute of Agricultural Research, \\ University of Ghana, \\ P.O. Box 38, Legon, \\ Ghana \\ $<$ _ynsiah@yahoo.co.uk> \\ ${ }^{3}$ Agricultural Extension Department, \\ School of Agriculture, \\ University of Ghana, \\ P.O. Box 68 , \\ Legon, \\ Ghana \\ <osakyid@ug.edu.gh> \\ ${ }^{4}$ Department of Soil Quality, \\ Wageningen University, \\ Droevendaalsesteeg 4, \\ NL-6708 PB Wageningen, \\ P.O. Box 47 \\ NL-6700 AA Wageningen \\ Pays-Bas \\ <thom.kuyper@wur.nl>
}

Tirés à part : T.W. Kuyper

\begin{abstract}
Résumé
Dans le cadre d'un programme interuniversitaire de recherche, Convergence des Sciences (CoS), une étude a été conduite sur les stratégies de gestion de la fertilité du sol dans les régions centrales du Ghana (Wenchi) et du Bénin (Savè) où des pratiques variables de gestion de la fertilité du sol sont adoptées. Les deux régions sont caractérisées par la présence de populations autochtones et migrantes qui diffèrent de par leurs stratégies de subsistance. Plusieurs modes de gestion foncière régissent l'usage de la terre par les autochtones et les migrants. Les modes d'accès à la terre ont évolué d'un arrangement basé sur l'échange de terre agricole contre force de travail à un système de location en espèces dû à la monétisation croissante de l'agriculture. Les autochtones accusent les migrants de dégrader les sols par leur pratique agricole intensive ; de leur côté, les migrants justifient leur pratique par l'insécurité foncière les obligeant à une agriculture minière. Conséquence immédiate, un climat de méfiance entre migrants et autochtones s'est installé. Les perspectives pour parvenir à un arrangement durable incluant la gestion durable des sols sont explorées. Cependant, la reconnaissance d'une interdépendance mutuelle constitue une base pour l'établissement de relations de confiance entre migrants et autochtones. L'étude analyse les ressemblances et dissemblances entre Wenchi et Savè en ce qui concerne les stratégies de production développées par les migrants, les pratiques de gestion de la fertilité du sol, et des modes de gestion du foncier. Un accent est mis sur les conséquences de différents modes de gestion du foncier sur la gestion de la fertilité du sol. L'article décrit également le processus de négociation initié pour un arrangement durable.
\end{abstract}

Mots clés : accès à la terre; dégradation du sol ; négociation ; politique foncière.

Thèmes : système agraire ; économie et développement rural ; territoire, foncier, politique agricole et alimentaire.

\section{Abstract}

Tenure security and soil fertility management: Case studies in Ghana and Benin

Within the framework of a larger research programme, Convergence of Sciences (CoS), studies were conducted on soil fertility management strategies in Ghana (Wenchi area) and Benin (Savè area). Soil fertility management in both areas includes short-term and longer-term practices. Both regions are characterised by the presence of natives and various groups of migrants that differ in their livelihood strategies. Natives and migrants enter into various tenure relationships. Driven by the increasing monetisation of the economy, such arrangements have evolved from land-for-labour relationships to a more monetary system,. In general natives claim that migrants are negatively affecting soil fertility through their cropping practices, while migrants claim that the nature of the tenure arrangement leads to insecurity and leaves them no choice but to mine the soil. There is, hence, widespread mistrust between natives and migrants, and the prospects for durable tenure arrangements that could maintain soil fertility seem limited. However, recognition of mutual interdependence could form a basis for the build-up of trust. In this study we highlight similarities and differences between the two areas in terms of livelihood strategies of migrants, soil fertility management practices and tenure arrangements. We also indicate the way in which alternative soil fertility management strategies could be effected under different tenure arrangements and describe the negotiation processes that have been started with a view to implementing such alternatives.

Key words: land access; land policies; negotiation; soil degradation.

Subjects: farming system; economy and rural development; territory, land use, agricultural and food production policy. 
$\mathrm{C}$ es dernières années, les conflits fonciers sont devenus des problèmes importants en Afrique au sud du Sahara. Ces conflits sont attribués à la pression induite par l'accroissement de la population avec pour conséquence une intensification de l'agriculture afin de satisfaire les demandes croissantes en produits sur le marché et à la migration des populations rurales (International Institute for Environment and Development, 1999; Toulmin et Quan, 2000 ; Cotula et al., 2003). Dans la plupart des régions d'Afrique de l'Ouest, les populations des zones arides, sont contraintes de se déplacer vers les zones plus humides du sud où les conditions environnementales sont plus favorables aux activités agricoles. Les zones de transition du Ghana et du Bénin accueillent un grand nombre d'immigrants provenant des savanes soudaniennes et cela depuis les années 1940 (Adjei-Nsiah et al., 2004; Saïdou et al., 2004). En plus des contraintes pédoclimatiques des régions d'origine des migrants, la présence dans les zones de migration de marchés où la demande pour les produits agricoles courants est importante, le développement d'une agriculture mécanisée à grande échelle (cas du Ghana) et le développement des cultures de rente comme le tabac, l'arachide et le coton, introduites du temps de l'Administration coloniale au début des années 1960 sont les autres causes ayant motivé le déplacement des populations agricoles (Adjei-Nsiah et al., 2007 ; Saïdou et al., 2007). Ces derniers facteurs ont suscité une demande accrue de maind'œuvre agricole en partie satisfaite par l'accueil de migrants.

Dans le passé, du fait de la faible population agricole dans les zones d'immigration, l'accès à la terre était facile. Les migrants pouvaient obtenir de la terre en faisant des dons symboliques en guise de présents pour les rituels (bouteilles d'alcool, noix de cola et argent) et en assurant des services en termes de maind'œuvre agricole pour les populations autochtones. De nos jours, en raison de la pénurie croissante de terre agricole dans les zones d'immigration, les modes d'accès à la terre ont évolué d'un arrangement à l'amiable vers un système plus formel, dont le métayage et le paiement en espèces d'une rente foncière. Dans certains cas, cette monétisation du foncier recherchée par certains propriétaires a conduit à des abus tels que le non-respect des accords initiaux lorsqu'une tierce personne fait une offre plus élevée, la loca- tion d'une même portion de terre à différentes personnes à la fois (cas du Ghana) et/ou une augmentation sans cesse du montant de la rente foncière (cas du Bénin). Au Ghana, en raison de l'inflation et par crainte d'une dégradation de la terre par le migrant, les propriétaires fonciers louent la terre pour une période maximum de deux ans contre le paiement à l'avance d'une forte rente foncière. Au Bénin, en raison de rentes foncières annuelles élevées, les migrants qui ne parviennent pas à payer sont menacés d'expulsion de la communauté. Le montant élevé des rentes et l'insécurité foncière empêchent les migrants d'investir dans des actions d'entretien de la fertilité des sols, ce qui affecte la qualité des sols par suite d'une baisse de leurs réserves en éléments minéraux et conduit à l'instauration d'une crise de confiance mutuelle entre migrants et propriétaires fonciers. La situation qui en a résulté dans ces deux pays est à l'origine de ce que certains ont appelé un dilemme social (Adjei-Nsiah et al., 2004 ; Saïdou et al., 2004).

L'étude proposée ici a été effectuée dans le cadre d'un programme interdisciplinaire conduit simultanément au Ghana et au Bénin (Convergence des Sciences pour une gestion intégrée des sols et des cultures - Hounkonnou et al., 2006). Les modes de gestion du foncier et de la fertilité des sols ont été étudiés et les options possibles pour le développement d'innovations en matière de gestion foncière ont été également identifiées. L'étude compare la situation dans les deux pays et discute des efforts consentis par les différentes parties prenantes pour la négociation d'arrangements durables garantissant à la fois la sécurité foncière et l'investissement dans des pratiques de restauration de la fertilité des terres.

\section{Méthodologie}

\section{Généralités sur la zone d'étude}

L'étude s'est déroulée dans les zones agro-écologiques du centre du Ghana et du Bénin. Ces zones ont été choisies à la suite d'un diagnostic préalable (AdjeiNsiah et al., 2004 ; Saïdou et al., 2004). Au Ghana, l'étude s'est déroulée dans le district de Wenchi. Trois villages ont été étudiés, à savoir: Asuoano $\left(7^{\circ} 41^{\prime} \mathrm{N}\right.$, $\left.2^{\circ} 06^{\prime} \mathrm{W}\right)$, Beposo ( $\left.7^{\circ} 41^{\prime} \mathrm{N}, 2^{\circ} 07^{\prime} \mathrm{W}\right)$ et Droboso $\left(7^{\circ} 42^{\prime} \mathrm{N}, 2^{\circ} 07^{\prime} \mathrm{W}\right)$. Les sols de la région sont surtout des sols ferralitiques et la végétation est caractéristique des zones de transition entre la zone forestière au sud et la zone des savanes au nord. Ces villages sont majoritairement (80\%) peuplés d'Akans, population autochtone, et de migrants (20\% de la population). Le groupe des migrants est composé par ordre d'importance de Wala, Dagarba, Mossi et Lobi. Les Lobi et les Mossi ont émigré du Burkina Faso dans les années 1940 et 1950 à la recherche de travail comme ouvriers agricoles dans les plantations de cacao ; en revanche, les Dagarba et les Wala ont émigré de la région occidentale du Ghana dans les années 1960 et 1990 respectivement. L'agriculture est l'activité principale des populations autochtones.

Au Bénin, l'étude a été conduite dans la région de Savè (entre $7^{\circ} 42^{\prime}$ et $8^{\circ} 45^{\prime} \mathrm{N}$ et $2^{\circ} 15^{\prime}$ et $\left.2^{\circ} 45^{\prime} \mathrm{E}\right)$. La zone comprend essentiellement des sols ferrugineux tropicaux avec présence, par endroits, de sols ferralitiques. La végétation est constituée par des savanes boisées et arborées avec présence d'îlots forestiers le long des cours d'eau. La population autochtone est composée de Tchabès appartenant au groupe des Yoruba et d'éleveurs peuhls sédentarisés. Depuis 1975, la zone a connu un afflux de migrants qui représentent actuellement $37 \%$ de la population de la région. Cet afflux a conduit à l'apparition de nouvelles communautés, à savoir les Ditammari, les Yom et les Waama (provenant de l'Atacora-Donga), les Fon (provenant du plateau d'Abomey) et les Idatcha (provenant de DassaZoumè et Glazoué). Les populations tchabè, spécialement ceux de la ville de Savè s'adonnent surtout aux activités de commerce, tandis que ceux qui vivent en milieu rural pratiquent l'agriculture. L'étude a été conduite dans cinq villages de migrants - Boubouhou, Elakpo, Igbo Iyoko, Kogbogoun et Ouoghi gare - et dans un village autochtone, Ouoghi centre.

\section{Méthodes de recherche}

L'étude a été conduite de janvier 2003 à mars 2005. Dans les deux pays, les informations ont été collectées à partir d'enquêtes collectives aussi bien auprès des groupes de migrants que des populations autochtones, avec une attention particulière portée à l'effet genre. Ces discussions de groupe ont été suivies d'entretiens individuels avec des producteurs et des personnes ressources, en particulier les leaders d'opinion. Les prin- 
cipales informations collectées ont concerné: les systèmes de culture, le processus d'accès à la terre et le mode de gestion du foncier, les stratégies de production développées par les différents groupes migrants, et les pratiques de gestion de la fertilité des sols.

Des plates-formes locales au niveau de chaque village et des plates-formes multiacteurs au niveau du district ont été organisées en vue de discuter des arrangements possibles pour une gestion durable de la tenure foncière. Au début du processus, les discussions au niveau des plates-formes se faisaient séparément avec les différents groupes socioculturels. Les plates-formes multi-acteurs étaient composées des différentes parties prenantes concernées par les problèmes fonciers, à savoir les services nationaux de vulgarisation, les équipes de recherchedéveloppement, la municipalité, les représentants des propriétaires fonciers, les organisations non gouvernementales (ONG), le représentant du roi, et les représentants des associations locales de développement. La périodicité des rencontres au niveau de ces forums a été trimestrielle. Le but était d'échanger sur les modalités possibles d'une gestion durable du foncier en milieu rural tout en préservant l'environnement. Par la suite, en février 2005, des représentants des différentes plates-formes locales et les membres de la plate-forme multi-acteurs ont été conviés à un forum foncier organisé au chef-lieu du district à l'initiative de l'équipe de recherche. Le but de cette rencontre qui a duré trois jours était de discuter des propositions faites par chaque groupe d'acteurs afin de parvenir à un arrangement foncier durable qui prenne en compte les problèmes de dégradation des terres.

Dans les deux pays, il a été également procédé à des observations directes dans les champs aussi bien des migrants que des populations autochtones afin de confirmer certaines informations relatives aux systèmes de culture.

\section{Résultats}

\section{Les systèmes de culture}

Au niveau des deux pays, les systèmes de culture varient en fonction des différents groupes socioculturels en présence. Dans la région de Wenchi, au Ghana, le maïs est la principale culture de rente, suivie de l'igname qui est également une culture vivrière. Le manioc et le taro sont les principales cultures vivrières. Le niébé et le pois d'angole ont une importance socio-économique dans la région. Le niébé est cultivé à la fois par les autochtones et les migrants. Les principales successions culturales pratiquées sont : igname, maïs en association avec le manioc (après la récolte du maïs, le manioc est cultivé en monoculture pendant 12 à 18 mois), maïs (pour bénéficier de l'arrière-effet du manioc), légumineuses à graines (niébé, arachide ou voandzou), taro, et le pois d'angole en fin de rotation. La différence de pratique entre les autochtones et les migrants se situe au niveau de la culture des plantes à cycle long comme le manioc, le pois d'angole et le taro. En effet, les autochtones et dans une certaine mesure les Lobi et les Mossi cultivent à la fois des cultures de rente et des cultures vivrières, tandis que les Wala pratiquent uniquement des cultures de rente, en particulier le maïs et le niébé.

Les stratégies de gestion de la fertilité des sols diffèrent d'un groupe socioculturel à l'autre. En général, les populations autochtones ont des pratiques de gestion de la fertilité des sols à long terme, à savoir la jachère naturelle et la rotation incluant des cultures à cycle long. Les anciens migrants, comme les autochtones, ont des pratiques de gestion de la fertilité des sols à long terme tandis que les migrants récemment installés, en particulier les Wala, ont des pratiques de gestion de la fertilité des sols à court terme comme le billonnage/buttage (pratique importée de leur région d'origine), la rotation culturale avec des cultures à cycle court telles que le niébé.

Dans la région de Savè au Bénin, les systèmes de culture des migrants sont en général orientés vers la commercialisation. Les principales cultures de rente sont le coton, le goussi (Citrullus colocynthis et $C$. lanatus), l'arachide, le soja, le riz, l'igname et le maïs qui sont en partie des cultures vivrières. Le sorgho, le niébé et le manioc sont les principales cultures vivrières. Les populations autochtones, en revanche, cultivent principalement pour la subsistance. En effet, les autochtones s'adonnent très peu aux cultures de rente car le commerce informel en particulier la vente du carburant frelaté et la conduite de taxi-moto localement appelée zémidjan leur permettent de générer des ressources substantielles pour la satisfaction des besoins de leur famille. Les principales cultures vivrières qu'elles pratiquent sont le manioc, le maïs, l'igname, le niébé et le goussi. Les cultures de rente sont l'anacarde, le piment, le coton et l'arachide. Les deux groupes pratiquent une agriculture sur brûlis pour la production de l'igname avec, pour conséquence, une forte pression sur les rares terres vierges.

Les principales successions culturales pratiquées par les migrants sont l'igname, le goussi (semé au début de la saison de culture), le maïs et le sorgho en association, le coton, le maïs, les légumineuses à graine (niébé, arachide ou soja) et le manioc (généralement en fin de rotation). Les principales associations culturales notées sont: maï/sorgho, maiis/manioc et arachide/maïs. Au niveau des autochtones, l'igname ou une légumineuse à graines ou le goussi sont cultivés généralement en tête de rotation ; ensuite viennent le maïs ou le coton, le sorgho ou le piment, le manioc, le maïs et l'anacardier (en fin de rotation, l'anacardier est la principale source de revenu agricole pour les autochtones, la parcelle n'est plus exploitée pour les cultures annuelles lorsque les arbres sont établis et la canopée fermée). Les associations culturales le plus souvent rencontrées sont : maïs/manioc, maïs/arachide, arachide/ anacarde. La jachère naturelle, la "jachère" manioc (le manioc a un cycle qui dure environ deux ans. Selon la perception paysanne, le rendement de la culture de maïs qui suit est nettement amélioré. À proprement parler, ce n'est pas une jachère car la parcelle porte la culture de manioc qui continue de prélever des nutriments du sol), les rotations culturales incluant des légumineuses à graines et l'utilisation d'engrais minéraux sont les principaux moyens de gestion de la fertilité des sols adoptés à la fois par les migrants et les producteurs autochtones. À l'opposé des autochtones, les migrants mettent en culture de vastes superficies. Cette différence s'explique par le fait que les migrants ont la possibilité d'engager des ouvriers agricoles, le plus souvent des migrants saisonniers ou de nouveaux migrants

$\mathrm{Au}$ niveau des deux pays, les rotations culturales céréales-légumineuses à graines, la culture du pois d'angole, la rotation coton-maïs, l'utilisation de la fumure minérale et la pratique de jachère de longue durée sont des pratiques qui améliorent la fertilité des sols soit par une augmentation du stock de matière organique dans le sol (cas de la jachère), soit en 
améliorant le stock de nutriments (cas de la fumure minérale et de l'introduction des légumineuses à graines qui par le processus de la fixation symbiotique améliorent la nutrition azotée de la plante). En revanche, les rotations céréales-céréales (exemple maïs-sorgho), l'association de deux céréales sur une même parcelle (exemple association maïs/sorgho, pratique répandue par les migrants), la pratique des feux de brousse qui accélère la minéralisation de la matière organique, la déforestation qui met à nu le sol et favorise l'érosion, sont des pratiques qui dégradent la fertilité des sols.

\section{Modes de gestion de la tenure foncière au Ghana et au Bénin}

\section{Modes d'accès à la terre}

Quatre principaux types de propriété de la terre existent en milieu rural à Wenchi au Ghana :

- La propriété du chef, connue sous le nom de terre du trône ou terre traditionnelle, gérée par un adjoint au chef ( $A b u s a$ hene) responsable de la gestion des ressources naturelles du chef, littéralement chef du métayage.

- Les terres familiales. Elles sont attribuées aux membres et descendants de la famille avec des droits de propriété octroyés par le représentant de chaque lignée suivant l'ordre d'héritage, ce système est connu sous le nom de Abusa panyin.

- Les terres individuelles. Ce sont des terres que des individus peuvent acquérir et exploiter. Les terres individuelles peuvent être acquises sous forme de présents ou dons des parents.

- Les terres sous contrôle gouvernemental. Ce sont des terres acquises par l'État en vue de leur reboisement. Ces terres sont habituellement distribuées aux paysans pour produire des cultures vivrières mais ceux-ci ont l'obligation de planter des arbres et de les entretenir pour l'État. Cette forme d'accès à la terre est connue sous le nom de système taungya. Les migrants, principaux bénéficiaires de ce système, sont supposés abandonner la parcelle après que les arbres se soient établis et que la canopée se soit fermée ; dans la réalité, les intéressés conservent leur parcelle. Traditionnellement, le droit de propriété sur la terre est basé sur les liens de parenté et cela sous le contrôle de l'autorité traditionnelle. Les membres de la famille matrilinéaire qui furent les premiers à défricher une parcelle ont le droit de la cultiver. Les femmes comme les hommes de la famille ont ainsi un droit d'usufruit sur la terre. On peut également avoir accès à la terre de la famille patrilinéaire. À l'exception du chef de Wenchi, personne ne peut vendre la terre à un étranger. La terre ne peut qu'être louée ou mise en métayage. Comme les migrants établis de manière permanente dans la région ne peuvent pas avoir de droit de propriété sur la terre, l'arrangement courant qui s'offre à eux est la location, le métayage ou le taungya.

Les terres des familles sont mises en location pour des périodes de courte durée par crainte de leur surexploitation par les migrants. Le loyer (la rente foncière) est le plus souvent payé à l'avance. Actuellement, le coût de location d'un hectare de terre s'élève à 500000 Cédi $^{1}$ (50 euros). En revanche, la durée de location des terres appartenant à la chefferie est illimitée; elle dure aussi longtemps que la rente foncière annuelle est payée. Le loyer n'est pas payé à l'avance mais à la fin de la saison de culture, généralement sous forme de produit agricole, en particulier de maïs. Il s'élève à un sac de $100 \mathrm{~kg}$ de maïs ou à son équivalent en argent. Actuellement la rente annuelle s'élève à 200000 Cédi $^{1}$ (20 euros).

On distingue deux modes de métayage selon le mode de partage de la récolte qui dépend du type de culture. Ce sont l'Abunu et l'Abusa. À Wenchi, le système Abusa s'applique aux cultures comme le maïs, exigeantes en intrants et en facteurs de production tels que la main-d'œuvre, les engrais minéraux et les herbicides. Le produit de la récolte est divisé en trois parties dont les deux tiers reviennent au métayer et le tiers restant au propriétaire foncier. Le système Abunu s'applique aux cultures comme le manioc moins exigeantes en intrants. Dans ce cas, le produit de la récolte est partagé à parts égales entre le propriétaire foncier et le métayer. Dans le cas de l'igname qui exige des dépenses initiales élevées, notamment pour l'achat des semenceaux, il n'existe pas de mode défini de partage des produits de la récolte. La part de la récolte octroyée au propriétaire foncier dépend de la bonne volonté du métayer.

Dans la région de Savè, deux types de gestion foncière existent (Le Meur, 2002).

\footnotetext{
$\overline{1}$ Devise officielle du Ghana depuis 1965.
}

Dans la région de Ouoghi, les propriétaires fonciers et les populations locales sont organisés au sein de l'Association de développement du village de Ouoghi (Adesvo). En fonction de leur intégration dans la communauté, les migrants ont la possibilité de négocier le montant des rentes foncières qu'ils ont à payer. Les rentes sont collectées par des groupes mandatés par l'Adesvo et sont utilisées principalement pour des investissements collectifs (construction de centres de santé et de réseaux d'adduction d'eau potable). Le second type, rencontré dans les villages de Boubouhou, Elakpo, Igbo Iyoko et Kogbogoun, est un système dans lequel les migrants versent les rentes foncières à des lignées ou collectivités de propriétaires fonciers de Savè, particulièrement la collectivité Amushu. Les rentes foncières payées ne sont pas utilisées pour des actions communautaires mais gérées par les chefs des collectivités.

Selon les règles coutumières, la terre est considérée par les populations autochtones comme un patrimoine sacré hérité des ancêtres et qui par conséquent ne peut être vendu à qui que ce soit. La terre peut être seulement attribuée ou transférée à des parents. Le droit de propriété des paysans autochtones correspond en fait à un droit d'usufruit, dépendant de l'appartenance à un groupe de la société ou à une lignée. Les exploitants autochtones acquièrent leur première parcelle de culture par héritage familial et/ou transfert de droits d'usage du chef de village. L'héritage se fait exclusivement au profit des enfants mâles qui ont tous les mêmes droits sur la terre. Suivant les règles coutumières, les enfants de sexe féminin n'héritent pas de la terre. Les femmes cultivent généralement les terres appartenant à leurs époux. En cas de divorce, la terre revient au mari ou à sa famille. En cas de décès du mari, la veuve conserve le droit d'usufruit sur la terre au nom de ses enfants de sexe mâle jusqu'à ce qu'ils atteignent l'âge de la majorité.

Les migrants en revanche sont tenus de payer une rente foncière annuelle de 15000 F CFA (23 euros). Cette rente foncière est indépendante de la surface cultivée. Cet arrangement ne leur donne pas le droit de planter des arbres ni même des légumineuses arbustives qui pourraient améliorer la fertilité du sol. Dans l'esprit des propriétaires fonciers, la plantation d'arbres est synonyme d'appropriation de la terre, ce qui pourrait accroître les droits des migrants sur la terre. 
Évolution du mode de gestion de la tenure foncière

À l'origine, les migrants dans la région de Wenchi avaient accès à la terre en offrant des boissons et une certaine somme d'argent au chef du village (Amanor, 1993). Ces présents offerts, le migrant pouvait ensuite mettre en culture autant de superficie que possible. À partir des années 1940, avec l'arrivée massive des migrants dans la région, le conseil traditionnel a commencé à réglementer l'accès à la terre sur la base du système Abusa qui impose aux migrants un loyer annuel de la terre. L'Abusa bene (chef métayage) fut alors créé pour gérer les terres du trône données en location aux migrants.

La plupart des migrants ont recours à diverses formes d'arrangement avec les paysans autochtones. Au début, les propriétaires fonciers préféraient avoir des contrats de métayage avec les migrants. Cependant, au fur et à mesure que la terre prenait de la valeur monétaire, les propriétaires fonciers ont préféré donner leur terre en location aux migrants en lieu et place des contrats de métayage pratiqués auparavant

De 1960 à 1985, le mode gestion du foncier dans le village de Ouoghi et la région de Boubouhou était similaire. Dans le cas du village de Ouoghi, le migrant désireux de s'installer dans la région, était introduit par son tuteur autochtone qui l'héberge auprès du balè (littérairement "père de la terre " jouant également le rôle de chef du village et de représentant des propriétaires fonciers et du kambiessi, roi de Savè). Dans le cas de Boubouhou et de ses environs, le migrant était introduit auprès des collectivités de propriétaires fonciers, groupes de familles, localement appelés omo onilè. Dans chacun des cas, le migrant offrait un ou deux litres de sodabi (boisson alcoolique locale distillée à partir du vin de palme) aux propriétaires fonciers ou au balè afin d'obtenir la bénédiction des ancêtres et des divinités pour que la terre soit prospère. À la fin de chaque saison culturale, le migrant offrait au chef de la collectivité des propriétaires fonciers ou au balè une quantité symbolique de produits vivriers en guise de reconnaissance. À partir de cet instant, le migrant était considéré comme hôte du village. Être hôte du village signifiait en contrepartie l'obligation de travailler comme ouvrier agricole pour son tuteur et le reste de la communauté.

De 1985 à 1990, les modalités de gestion de la tenure foncière ont évolué. Dans le village de Ouoghi, les migrants continuent d'offrir des boissons alcoolisées, quelques noix de colas et une somme de 2000 F CFA (3 euros) qui représente le droit d'accès à la terre (itchakolè en langue locale), lequel se paie une seule fois à l'installation du migrant. Dans la région de Boubouhou, en plus des présents qui sont offerts, le migrant paie également selon la proximité de la parcelle et l'état de fertilité du sol une somme variant entre 5000 et 7000 F CFA (8 à 11 euros) en guise de itchakolè (Berry, 1993; Le Meur, 2002). Le tribut inclut également l'obligation pour le migrant de travailler comme ouvrier agricole pour le propriétaire foncier. Mais cette obligation compensatoire de travailler comme ouvrier agricole a disparu à partir de 1991. À partir de cette date, l'arrangement institutionnel de gestion du foncier dans le village de Ouoghi est devenu plus formel avec l'instauration d'un document établi d'un commun accord entre l'Adesvo et les migrants, régissant l'accès à la terre. Bien que de telles règles soient écrites, elles n'avaient pas un statut véritablement juridique. Le balè a perdu ses prérogatives dans la gestion des terres en faveur de l'Adesvo. En lieu et place des boissons alcoolisées et des noix de colas, les migrants sont tenus de payer un itchakolè de 5000 F CFA (8 euros) auquel s'ajoute à la fin de chaque saison culturale le paiement d'une taxe annuelle d'exploitation de la terre de 2000 F CFA (3 euros) par hectare. Cette taxe d'exploitation des terres s'est accrue jusqu'à 5000 F CFA (8 euros) au cours de la période 19941998, mais la terre est toujours gérée collectivement et les rentes collectées sont utilisées pour des actions de développement dans le village. Les anciens migrants vivant dans le village depuis au moins 10 à 15 ans sont considérés comme des membres de la communauté : ils sont, de ce fait, moins taxés ou même exemptés de paiement de rente. À l'opposé, les migrants sont plus taxés dans la région de Boubouhou : 5000 à $10000 \mathrm{~F} \mathrm{CFA} \mathrm{(8} \mathrm{à}$ 15 euros) d'itchakolè et une taxe annuelle de 10000 F CFA (15 euros) par hectare. À partir de 1999, le montant de la rente foncière à payer par hectare a été fixé à $5000 \mathrm{~F} \mathrm{CFA} \mathrm{(8} \mathrm{euros)} \mathrm{dans} \mathrm{les} \mathrm{deux}$ régions. Étant donné que les propriétaires fonciers n'arrivent pas à estimer les superficies mises en culture par chaque migrant, la taxation est basée forfaitairement sur une superficie minimum de trois hectares, soit une rente annuelle de
15000 F CFA (23 euros) même si l'intéressé cultive moins de trois hectares.

\section{Gestion des conflits fonciers en milieu rural au Ghana et au Bénin et perspectives pour un arrangement durable prenant en compte la préservation de l'environnement}

Au Ghana, le métayage entraîne souvent des conflits entre les propriétaires fonciers et les migrants. Les propriétaires fonciers accusent les migrants de fraude ou d'utiliser pour leur propre compte une partie de la récolte à partager, spécialement pour le maïs. En effet, le métayage concernant la culture du maïs conduit souvent à des conflits en raison de la consommation du produit par la famille du migrant avant même que le produit de la récolte ne soit partagé avec le propriétaire foncier. Les migrants justifient cela par le fait qu'ils ne peuvent pas acheter de produits vivriers pour nourrir leur famille alors qu'ils en disposent dans leur champ. Des conflits plus sérieux apparaissent lorsque la terre est mise en location. En raison de la rente foncière qui ne cesse de croître, les migrants ont tendance à produire de façon continue, durant la période de location, des cultures à haute valeur économique comme le mais sans aucune pratique d'entretien de la fertilité des sols. De telles pratiques conduisent à la baisse des nutriments du sol. Aussi pour limiter cette dégradation de la fertilité des sols par les migrants, les propriétaires fonciers mettent rarement en location les terres au-delà de deux ans. Cette situation génère une insécurité foncière pour les migrants qui se plaignent de l'absence de garanties leur permettant de bénéficier des fruits des investissements qui seraient faits dans l'entretien de la fertilité des sols du fait de la courte durée de la location de la terre. Parfois, les propriétaires fonciers remettent en cause les contrats de location des terres avant leur expiration. C'est le cas particulièrement lorsque le locataire a de bons rendements sur une parcelle, avec comme principale raison qu'ils veulent céder cette parcelle à un de leur fils. Il arrive aussi que certains propriétaires fonciers louent la même parcelle à deux locataires différents.

En raison des difficultés rencontrées par les migrants, bon nombre d'entre eux ont recours de nos jours à des contrats écrits, 
rédigés par des officiels assermentés. Lesdits contrats mentionnant les noms des deux parties, la superficie et la forme de location de la parcelle ainsi que la durée du contrat, sont signés par les deux parties contractantes en présence de leurs témoins. Cependant, lorsque le contrat n'est pas avalisé par un témoin influant, membre de la famille du propriétaire tel que le fils ou la fille aîné€ ou le chef de famille, la validité du contrat peut être contestée et le locataire peut être évincé de la parcelle avant la période d'expiration du contrat. De tels conflits traduisent la tension bien connue entre d'une part l'ambiguité, la flexibilité et l'indétermination des règles d'utilisation de la terre (Berry, 1993 ; Berry, 2002) et les rapports de force (Peters, 2002 ; Peters, 2004) qui sont souvent en défaveur du migrant, d'autre part.

Dans le cas du Bénin, le mode de paiement des rentes foncières est la principale source de conflit entre les migrants et la collectivité des propriétaires fonciers. Parfois, les anciens migrants agissent en lieu et place des propriétaires fonciers et collectent les rentes auprès des nouveaux migrants à l'insu des propriétaires fonciers. Le nouveau migrant a l'obligation de travailler comme ouvrier agricole pour l'ancien migrant avant qu'un lopin de terre ne lui soit attribué. Dans cette situation, les propriétaires fonciers sont abusés car ils n'entrent pas en possession de la rente pendant que le migrant améliore sa situation financière et cultive une plus grande superficie. En outre, certains migrants plantent des anacardiers malgré l'interdiction de planter des arbres sur les terres louées. De 2003 à 2004, la tension entre les propriétaires fonciers et les migrants s'est accentuée à cause du nonpaiement des rentes foncières avec, pour conséquence, le départ de certains migrants pour le Nigeria où les règles de gestion foncière paraissent plus favorables à celles pratiquées dans la région de Savè. En général, les tensions avec les collectivités des propriétaires fonciers sont plus fréquentes dans la région de Boubouhou et de Savè comparativement au village de Ouoghi.

Au cours du temps, le processus de collecte des rentes a changé. Dans le passé, la plupart des migrants cultivaient le coton, seule culture à posséder une filière bien organisée avec des intrants délivrés à crédit, un service de vulgarisation et un circuit de commercialisation organisés par l'État, un prix d'achat du coton fixé à l'avance et des organisations paysannes fonctionnelles. Grâce à l'inventaire des producteurs de coton, les propriétaires fonciers étaient informés du nombre de migrants vivants dans la zone. Un accord avait été établi entre les propriétaires fonciers et les organisations paysannes UCPC (Union communale des producteurs de coton) et GPC (Groupement des producteurs de coton) au niveau du village afin de prélever la rente annuelle sur le montant de la vente du coton. Ce système a fonctionné efficacement jusqu'à ce que la filière cotonnière connaisse des difficultés financières et organisationnelles sur le plan national (Sinzogan et al., 2007). De nos jours, très peu de migrants continuent de cultiver le coton, ce qui fait que les propriétaires fonciers ne sont plus informés de l'arrivée de nouveaux migrants. Les difficultés qu'a connues la filière cotonnière ont entraîné une perte de confiance entre les propriétaires fonciers et les migrants.

\section{Discussion et conclusion}

\section{Mode de gestion du foncier et son impact sur la gestion de la fertilité des sols}

Au Ghana, les anciens migrants (Lobi, Mossi et Dagarba) ont établi de longue date de solides relations avec les populations autochtones, ils ont pu ainsi obtenir une sécurité foncière et des accès de longue durée à la terre comparativement aux Wala, migrants récemment installés. Les différences de pratiques de gestion de la fertilité des sols entre les différents groupes socioculturels dépendent des stratégies de production. Ainsi les Wala cherchent à accumuler des richesses qui seront ensuite exportées dans leur village d'origine où ils comptent retourner. Ce comportement des Wala a des conséquences sur la gestion de la fertilité des sols car leur réussite relative peut inciter d'autres migrants à adopter également des pratiques qui dégradent les terres.

Dans le cas du Bénin, la qualité des rapports entre les populations autochtones et les migrants dépend des communautés locales et de leurs perspectives. L'intégration des migrants dans la communauté contribue à leur assurer une certaine sécurité foncière. Par ailleurs la contribution des migrants à l'économie locale a favorisé une interdépendance avec les populations autochtones.

Dans les deux pays, les populations autochtones tirent l'essentiel de leur revenu de la culture du maïs (cas du Ghana) et de l'anacarde (cas du Bénin). Comme l'anacardier est un arbre fruitier et donc une culture pérenne, la plantation d'anacardiers est une stratégie adoptée par les populations autochtones pour assurer leur retraite. Au Bénin, " la jachère manioc " est une pratique culturale adoptée par les migrants pour accroitre leur droit de propriété sur la terre ; en revanche, les Wala au Ghana sont réticents à cultiver le manioc et le pois d'angole parce qu'ils occupent la terre pendant une longue période alors qu'ils ne sont pas autorisés à louer la terre pour une période supérieure à deux ans.

En raison de l'insécurité foncière, la pratique de la jachère de longue durée au Bénin peut avoir comme conséquence pour le migrant la perte des droits d'exploitation de la terre. En effet, une jachère de longue durée peut être considérée comme un terrain non occupé et par conséquent être attribué à un nouveau migrant. Cette situation explique pourquoi la plupart des migrants pratiquent des jachères de courte durée $(2$ ou 3 ans). Au Ghana, en raison de la courte durée des périodes de location des terres, les migrants sont peu enclins à investir dans des pratiques à long terme de gestion de la fertilité du sol. Comme les migrants qui louent la terre n'ont aucune garantie de pouvoir jouir pleinement des avantages à long terme que procurerait un investissement dans l'amélioration de la fertilité du sol, il est évident qu'ils privilégient des stratégies de gestion du sol qui maximisent la production à court terme même si celles-ci compromettent la fertilité du sol (Gavian et Fafchams, 1999 ; Frazer, 2004).

Bien que plusieurs techniques de restauration de la fertilité des sols, dont les plantes de couverture, l'agroforesterie et les engrais minéraux, aient été introduites au Ghana et au Bénin par les services d'encadrement du monde rural, l'insécurité foncière empêche les migrants de les adopter. Aussi les modalités des accords d'exploitation des terres entre les migrants et les propriétaires fonciers doivent être reconsidérées afin de favoriser des accords à long terme permettant d'assurer le maintien de la fertilité des sols. 


\section{Perspectives pour une gestion durable de la fertilité des sols}

De tels arrangements seront acceptables par les deux parties s'ils n'affectent pas les rapports de force existants. Cela implique que ces arrangements doivent être attractifs pour les populations autochtones (paiement régulier des rentes et maintien de la fertilité des sols) et pour les migrants (sécurité foncière à long terme). Cela ne peut être atteint qu'à travers la négociation. Comme l'a souligné Leeuwis (2004), une condition primordiale pour la réussite des négociations est l'interdépendance mutuelle entre les acteurs en présence. Les populations autochtones et les migrants sont conscients de cette interdépendance en dépit des plaintes sur la dégradation des sols et la baisse du rendement des cultures. La principale question qui se pose est comment intégrer les techniques de restauration de la fertilité des sols dans les règles d'utilisation actuelles des terres?

Quand certains groupes de migrants sont bien intégrés dans leur communauté d'accueil, le processus de négociation d'un arrangement pour une meilleure gestion de la tenure foncière est relativement facile, comme c'est le cas dans le village de Ouoghi au Bénin ou des Mossi, des Dagarba et des Lobi au Ghana. En revanche, la négociation entre les propriétaires fonciers et les Wala au Ghana et entre les migrants de la région de Boubouhou et les propriétaires fonciers de Savè au Bénin a été difficile en raison des intérêts et objectifs divergents des différents groupes. D'une manière générale, on peut conclure que, dans les situations où la population paysanne est très hétérogène en termes de stratégie d'activité, l'adoption de meilleures techniques de gestion des sols et la négociation d'un arrangement social pour l'adoption de ces techniques seront plus difficiles. Cela étant, des efforts doivent être entrepris pour la mise au point d'une gamme d'options techniques et sociales à faire approuver par les différentes parties pour leur permettre d'atteindre leurs objectifs spécifiques.

Les efforts entrepris pour la négociation d'un arrangement alternatif pour la gestion de la tenure foncière entre les migrants et les propriétaires fonciers n'ont pas été fructueux à Wenchi du fait qu'un groupe de migrants n'était pas disposé à en discuter au niveau d'une plateforme de négociation. Cette situation s'explique par le fait que la gestion du foncier est un problème sensible qui implique plusieurs parties prenantes, dont le chef du village. Les différentes parties prenantes sont attachées à leurs intérêts particuliers ; les propriétaires fonciers en particulier craignent un changement du rapport de force existant qui serait en faveur des migrants. Cependant, certains migrants et propriétaires fonciers ont élaboré, à titre expérimental, de nouvelles formes alternatives d'arrangement où les rentes foncières sont payées sous forme de produits agricoles après la récolte. Mais ces expériences ont été également infructueuses en raison de l'inexistence de règles écrites bien définies régissant le contrat de tenure foncière. Par ailleurs, la validité des contrats est souvent remise en cause par les enfants des propriétaires fonciers qui ne sont pas toujours impliqués dans l'établissement des contrats. Malgré cela et en dépit des difficultés rencontrées lors de son expérimentation, certains groupes, en particulier les populations autochtones, les Dagarba et les migrants qui ne sont pas en mesure de payer à l'avance les rentes foncières sont favorables pour cet arrangement qui consiste à payer la rente foncière sous forme de produits agricoles après la récolte. Il s'avère alors utile de développer un cadre de concertation pour la gestion des terres au niveau local basé sur la recherche de solutions pragmatiques en tenant compte des expériences passées, et de principes fondamentaux, à savoir la transparence, l'équité, et la recherche de consensus (Berry, 2002). Il est également nécessaire de renforcer la capacité des institutions coutumières et traditionnelles pour la résolution des conflits et la gestion de la tenure foncière au niveau local (FredMensah, 1999).

Dans le contexte du Bénin, l'arrangement alternatif qui a été négocié comprend l'établissement d'un contrat écrit comportant l'autorisation pour les migrants de planter des légumineuses arbustives fixatrices d'azote atmosphérique, de pouvoir bénéficier d'une certaine sédentarisation nécessaire pour la culture d'igname et l'adoption de pratiques améliorées de gestion de la fertilité des sols. La négociation de cet arrangement a changé le point de vue des propriétaires terriens sur la plantation des arbres qui ne signifie plus pour eux une appropriation tacite de la terre mais qui doit être également perçue comme une pratique culturale contribuant à la régénération et la protection des terres. En dehors des points positifs que cet arrangement présente, des contraintes sont cependant à mentionner. De multiples techniques de restauration de la fertilité des sols existent mais l'on ne peut être assuré de leur adoption par les migrants dont les stratégies et les systèmes de culture sont basés sur l'accumulation de revenus à court terme. En effet, l'adoption de ces techniques exige des coûts supplémentaires spécialement en main-d'œuvre (Adégbola et al., 2002) dont les bénéfiques économiques ne sont pas immédiats.

Ces arrangements alternatifs ont été négociés sur la base des plates-formes locales et des plates-formes multi-acteurs. La plate-forme lieu de discours coopératifs (Webler et al., 1995; Steins et Edwards, 1999) encourage les différentes parties prenantes à s'engager dans des actions collectives en vue de concilier les objectifs de chacune des parties. La condition sine qua non consiste à créer les conditions pour l'établissement d'une confiance mutuelle en montrant par exemple que l'amélioration de la fertilité des sols permettra d'accroître le rendement des cultures et par conséquent facilitera la capacité des migrants à payer la rente foncière annuelle.

\section{Références}

Adégbola YP, Sodjinou E, Housou N, Singbo GA. Étude financière et socio-économique des technologies de gestion de la fertilité des
sols au Sud-Bénin. Rapport d'étude. Cotonou: PAPA/INRAB, 2002.

Adjei-Nsiah S, Leeuwis C, Giller KE, et al. Land tenure and differential soil fertility management practices in Wenchi, Ghana: implication for interdisciplinary action research. NJAS Wag J Life Sc 2004 ; 52 : 331-48.

Adjei-Nsiah S, Leeuwis C, Sakyi-Dawson O, Giller KE, Kuyper TW. Exploring diversity among farmers for orienting inter-disciplinary among farmers for orienting inter-disciplinary ment in Wenchi, Ghana: the significance of time horizons. Int J Agric Sust $2007 ; 5$ : 176-94.

Amanor KS. Wenchi farmer training project: social/environmental baseline study. Rapport d'étude. London: Overseas Development Administration, 1993.

Berry S. No condition is permanent : the social dynamics of agrarian change in Sub-Saharan Africa. Madison: Presses de I'Université de Wisconsin, 1993.

Berry S. The everyday politics of rent-seeking : land allocation on the outskirts of Kumasi, Ghana. In: Juul K, Lund C, eds. Negotiating Property in Africa. Portsmouth: Heinemann, 2002. 
Cotula L, Toulmin C, Hesse C. Land tenure, land reform and land administration in Africa : lessons of experience and emerging issues. A draft report prepared for the FAO by The International Institute for Environment and Development (IIED). Edinbourgh: Drylands Programme, IIED, 2003.

Fraser DGE. Land tenure and agricultural management : soil conservation on rented and owned fields in southwest British Columbia. Agric Human Values $2004 ; 21$ : 73-9.

Fred-Mensah BK. Capturing ambiguities : communal conflict management alternative in Ghana. World Dev 1999 ; 27 : 957-65.

Gavian S, Fafchamps M. Land tenure and allocative efficiency in Niger. Am J Agric Econ $1996 ; 78: 460-71$.

Hounkonnou D, Kossou D, Kuyper TW, et al. Convergence of sciences : the management of agricultural research for small-scale farmers in Benin and Ghana. NJAS - Wag J Life Sc 2006 ; $53: 343-67$.
International Institute for Environment and Development (IIED). Land tenure and resource access in West Africa: issues and opportuni ties for the next twenty five years. London IIED, 1999.

Leeuwis C. Communication for rural innovation : rethinking agricultural extension. $3^{\mathrm{e}}$ ed. Oxford : Blackwell Science, 2004.

Le Meur PY. Trajectories of the politicisation of land issues: case studies from Benin. In : Juul K, Lund C, eds. Negotiating Property in Africa. Portsmouth : Heinemann, 2002.

Peters PE. The limits of negotiability : security, equity and class formation in Africa's land systems. In : Juul K, Lund C, eds. Negotiating Property in Africa. Portsmouth: Heinemann, perty
2002.

Peters PE. Inequality and social conflict over land in Africa. J Agrar Change 2004 ; 4 : 269314.
Saïdou A, Kuyper TW, Kossou D, Tossou R, Richards P. Sustainable soil fertility management in Benin : learning from farmers. NJAS Wag J Life Sc 2004 ; 52 : 349-69.

Saïdou A, Tossou R, Kossou D, Sambieni S, Richards P, Kuyper TW. Land tenure and sustainable soil fertility management in Benin. Int J Agric Sust 2007 ; 5 : 195-212.

Sinzogan AAC, Jiggins J, Vodouhè S, Kossou DK, Totin E, van Huis A. Cotton industry institutional linkages in Benin: stakeholder analysis and actor perspectives. Int J Agric Sust $2007 ; 5: 213-31$.

Steins N, Edwards V. Platforms for collective action in multiple use common pool resources. Agric Human Values 1999 ; 16 : 241-55.

Toulmin C, Quan J. Evolving land rights, policy and tenure in Africa. London: DFID/IIED/NRI, 2000.

Webler T, Kastenholz H, Renn O. Public participation and impact assessment: a social learning perspective. Envir Impact Ass Review $1995 ; 15: 443-63$. 